\title{
MDM2 antagonist Nutlin-3a protects wild-type p53 cancer cells from paclitaxel
}

\author{
SHEN HongChang, DONG Wei, GAO DongWei, WANG GuangHui, MA GuoYuan, \\ LIU Qi ${ }^{*} \&$ DU JiaJun
}

Department of Thoracic Surgery, Provincial Hospital Affiliated to Shandong University, Shandong University, Jinan 250021, China

Received April 14, 2011; accepted July 27, 2011

\begin{abstract}
The p53 pathway has an important role in cell cycle arrest and apoptosis. Downregulated levels of p53 have been shown to increase resistance to the cytotoxic effects of chemotherapy or radiotherapy. MDM2 (murine double minute 2) is able to bind p53 and modulate its transcriptional activity and stability. We studied the effect of Nutlin-3a, an MDM2 antagonist, on the response of non-small cell lung cancer cell lines, A549 (p53+/+) and H1299 (p53-/-), to paclitaxel (Taxol). A549 cells treated with Nutlin-3a plus paclitaxel showed a significant increase in MDM2 and wild-type p53 protein, a marked increase in the number of cells in the G0-G1 and G2-M phases, and a significant decrease in the percentage of cells in the S phase. The percentage of apoptotic A549 cells treated with $10 \mu \mathrm{mol} / \mathrm{L}$ Nutlin-3a plus $10 \mathrm{nmol} / \mathrm{L}$ paclitaxel was significantly lower than those treated with paclitaxel alone, and was also lower than that observed in $\mathrm{H} 1299$ cells. MTT assays demonstrated that Nutlin-3a plus paclitaxel also significantly reduced the sensitivity of A549 cells to paclitaxel compared with that of H1299 cells. In conclusion, Nutlin-3a mediates the cytotoxic effect of paclitaxel depending on p53 status. It may also protect wild-type p53 cells from mitotic chemotherapeutics.
\end{abstract}

non-small cell lung carcinoma, p53, MDM2 antagonist, paclitaxel

Citation: Shen H C, Dong W, Gao D W, et al. MDM2 antagonist Nutlin-3a protects wild-type p53 cancer cells from paclitaxel. Chin Sci Bull, 2012, 57: 1007-1012, doi: 10.1007/s11434-012-4984-7

Lung cancer is the leading cause of cancer-related deaths in the world with the number of deaths more than 1180000 annually [1]. Because $65 \%$ of lung cancer patients are in the advanced stage, and about $80 \%$ of lung cancer is composed of non-small cell carcinomas (NSCLC), chemotherapy is the main treatment. However, NSCLC is more resistant to chemotherapy than other forms of cancer [2,3]. Therefore, the development of a novel and efficient therapy to sensitize NSCLC to chemotherapy is urgently required.

The p53 pathway has an important role in cell cycle arrest and apoptosis. Defects in the p53 network are thought to be involved in a massive percentage of tumors $[4,5]$. Restoration of the p53 tumor suppressor pathway should, in theory, trigger considerable apoptosis of the tumor. In addition, downregulated levels of p53 have been shown to in-

*Corresponding authors (email: dujiajun66@tom.com; liuqi66@sdu.edu.cn) crease resistance to the cytotoxic effects of chemotherapy or radiotherapy [6,7]. Hence, p53 is an appealing target for novel anticancer therapeutic strategies.

Murine double minute 2 (MDM2) is the primary negative regulator of p53, and is an E3 ubiquitin ligase that transports p53 to the cytoplasm, where it promotes p53 ubiquitination and degradation by the proteasome [8]. In proliferating cells, p53 levels are tightly controlled by MDM2, which modulates its transcriptional activity and stability following binding [9-11]. MDM2 and p53 form a negative feedback loop [12]; therefore, it is possible to activate the p53 pathway by inhibiting MDM2.

Recently, small-molecule inhibitors of MDM2, Nutlins, have been developed, and found to have a high affinity for MDM2, preventing binding to p53 [13-15]. Nutlins can release p53 from the negative control of MDM2 and activate the $\mathrm{p} 53$ pathway to promote cell cycle arrest and apop- 
tosis in cancer cells that express wild-type p53. Nutlin-3a increases radiosensitivity of $\mathrm{H} 460$ and Val138 cells [16], and sensitizes cancer cells to chemotherapeutic agents such as cisplatin, and etoposide [17]. However, some researchers found that Nutlins can protect non-malignant cells and tissues $[18,19]$. Therefore, it is not clear whether Nutlins are effective agents for chemosensitization, or are able to protect cells from chemotherapy in wild-type p53 and p53deficient cancer cells.

The objective of this study was to evaluate the effects of Nutlins on NSCLC cell lines, A549 (wild-type p53) and H1299 (p53-deficient), when used in conjunction with a commonly used chemotherapeutic, paclitaxel.

\section{Materials and methods}

\subsection{Cell culture}

Human NSCLC cell lines A549 and H1299 were cultured in RPMI-1640 with $10 \%$ fetal calf serum (FBS, Gibco, Grand Island, NY, USA) and Dulbecco Modified Eagle Medium supplemented with $10 \% \mathrm{FBS}$ at $37^{\circ} \mathrm{C}$ in $5 \% \mathrm{CO}_{2}$, respectively. Cells were used when in the exponential growth phase.

\subsection{Reagents}

Nutlin-3a (Sigma-Aldrich, St. Louis, MO, USA) was dissolved in DMSO and stored as $20 \mathrm{mg} / \mathrm{mL}$ stock solution in small aliquots at $-20^{\circ} \mathrm{C}$ to avoid repeated freeze-thaw cycles. A stock solution of $1 \times 10^{6} \mathrm{nmol} / \mathrm{L}$ paclitaxel (Hainan Shunyuan Chemotech, Hainan, China) diluted in alcohol was stored at $-20^{\circ} \mathrm{C}$. Anti-MDM2 (SMP14) and anti-p53 (DO-1) antibodies were purchased from Santa Cruz Biotechnology Inc. (Santa Cruz, CA, USA). Anti- $\beta$-actin (AC-15) antibody was from Sigma-Aldrich. All other reagents were from Sigma-Aldrich unless otherwise stated.

\subsection{Western blot analysis}

A549 and H1299 cells were incubated with $10 \mu \mathrm{mol} / \mathrm{L}$ Nutlin-3a, $10 \mathrm{nmol} / \mathrm{L}$ paclitaxel and a combination of $10 \mu \mathrm{mol} / \mathrm{L}$ Nutlin-3a $+10 \mathrm{nmol} / \mathrm{L}$ paclitaxel in $25 \mathrm{~cm}^{2}$ flasks in $5 \mathrm{~mL}$ medium for $8 \mathrm{~h}$. Cells were harvested and lysed in protein lysis buffer. Equal amounts of protein lysate were loaded into each well and separated by $10 \%$ sodium dodecylsulfatepolyacrylamide gel electrophoresis for $2 \mathrm{~h}$ at $100 \mathrm{~V}$, followed by transferring proteins to a nitrocellulose membrane (Amersham Biosciences, Piscataway, NJ, USA). Membranes were incubated with primary antibodies against p53 (1:500; Santa Cruz Biotechnology), MDM2 (1:500; Santa Cruz Biotechnology), and $\beta$-actin (Sigma-Aldrich) overnight at $4{ }^{\circ} \mathrm{C}$, followed by secondary horseradish peroxidaseconjugated goat anti-mouse antibody $(1: 2000$; Sigma-
Aldrich). $\beta$-actin was used for loading control in all experiments. Proteins were traced by enhanced chemiluminescence Western blot detection reagent (Amersham Biosciences). Optical density (OD) protein levels were normalized to corresponding $\beta$-actin and results were expressed as an OD ratio.

\subsection{Cell cycle analysis}

A549 and H1299 cells were treated with a DMSO vehicle (untreated control), $5 \mu \mathrm{mol} / \mathrm{L}$ Nutlin-3a, $10 \mathrm{nmol} / \mathrm{L}$ paclitaxel or a combination of $5 \mu \mathrm{mol} / \mathrm{L}$ Nutlin-3a and $10 \mathrm{nmol} / \mathrm{L}$ paclitaxel for $48 \mathrm{~h}$. After treatment, cells were collected with $0.25 \%$ Trypsin (Gibco) and washed twice in 0.01 $\mathrm{mol} / \mathrm{L}$ PBS. After centrifugation at $2000 \mathrm{r} / \mathrm{min}$ for $5 \mathrm{~min}$, cells were suspended in PBS and fixed in ice-cold ethanol $(70 \%, v / v)$ at $4{ }^{\circ} \mathrm{C}$ overnight and stained with $1 \mathrm{~mL}$ propidium iodide (PI) solution (50 $\mu \mathrm{g} / \mathrm{mL}$ PI, $100 \mu \mathrm{g} / \mathrm{mL}$ RNAase A, 10 $\mathrm{mmol} / \mathrm{L}$ EDTA, $0.5 \%$ Triton $\mathrm{X}-100$ ) at $4^{\circ} \mathrm{C}$ for $30 \mathrm{~min}$ in the dark. Cell cycle distribution of samples was determined using a FACScan flow cytometer (Becton, Dickinson and Company, Franklin Lakes, NJ, USA), and data were analyzed using ModFit and CellQuEST software (Becton, Dickinson and Company).

\subsection{Cell apoptosis analysis}

A549 and H1299 cells were treated with a DMSO vehicle (untreated control), $5 \mu \mathrm{mol} / \mathrm{L}$ Nutlin- $3 \mathrm{a}, 10 \mathrm{nmol} / \mathrm{L}$ paclitaxel or a combination of $5 \mu \mathrm{mol} / \mathrm{L}$ Nutlin-3a and $10 \mathrm{nmol} / \mathrm{L}$ paclitaxel for $48 \mathrm{~h}$. After treatment, cells were collected with $0.25 \%$ Trypsin and washed twice in chilled $0.01 \mathrm{~mol} / \mathrm{L}$ PBS. After centrifugation at $2000 \mathrm{r} / \mathrm{min}$ for $5 \mathrm{~min}$, cells were suspended in Flow Cytometry Buffer and adjusted to a concentration of $1 \times 10^{6}$ cells $/ \mathrm{mL}$. Next, $5 \mu \mathrm{L}$ AnnexinV/ FITC and $10 \mu \mathrm{L}$ PI solution were added to $100 \mu \mathrm{L}$ cell suspension for $15 \mathrm{~min}$ in the dark. Samples were measured using a FACScan flow cytometer (Becton, Dickinson and Company). Cell apoptosis was analyzed using WinMDI2.9 software (Becton, Dickinson and Company).

\subsection{MTT assays}

The 3-(4,5-dimethylthiazol-2-yl)-2,5-diphenyltetrazoliumbromide (MTT, Sigma-Aldrich) assays were used to survey and evaluate cell survival in a quantitative colorimetric assay. The cells $\left(3 \times 10^{3} /\right.$ well) were seeded into 96 -well plates and incubated at $37^{\circ} \mathrm{C}$ in RPMI-1640 and DMEM mediums respectively. After 24 h culture, A549 and H1299 cells were treated with varying concentrations of paclitaxel $(0,0.1,1$, $10,100,1000 \mathrm{nmol} / \mathrm{L})$ and Nutlin-3a $(0,5,10,15 \mu \mathrm{mol} / \mathrm{L})$ for $72 \mathrm{~h}$, and $10 \mathrm{nmol} / \mathrm{L}$ paclitaxel and/or $5 \mu \mathrm{mol} / \mathrm{L}$ Nutlin$3 \mathrm{a}$ for variable time points $(0,24,48,72 \mathrm{~h})$ in quintuplet. Medium alone, and medium plus DMSO acted as control 
for each dilution. A $20 \mu \mathrm{L}$ volume of MTT was added to each well, then plates were incubated for an additional $4 \mathrm{~h}$ at $37^{\circ} \mathrm{C}$. The medium was then removed and replaced with $150 \mu \mathrm{L}$ DMSO in each well. Plates were shaken for $15 \mathrm{~min}$ at room temperature, and read at $490 \mathrm{~nm}$ in a Bio-Rad 680 Microplate reader (Bio-Rad Laboratories, Inc., Berkeley, CA, USA).

\subsection{Statistical analysis}

Data were expressed as means \pm standard deviations (SD). Statistical significance between groups was determined by the analysis of variance and Student-Newman-Keuls multiple comparison test ( $q$ test) after confirming the equality of variance with the Levene test using SPSS statistical software version 13.0 (SPSS Inc., Chicago, IL, USA). $P<0.05$ was deemed statistically significant.

\section{Results}

\subsection{Expression of p53 and MDM2 protein}

Expression of wild-type p53 and MDM2 protein was determined by Western blot. As shown in Figure 1, wild-type p53 is expressed in A549 cells but not in H1299 cells, while MDM2 is expressed in both A549 and H1299 cell lines. The addition of Nutlin-3a to A549 cells resulted in dose-dependent increases in $\mathrm{p} 53$ and MDM2 protein expressions. In contrast, there was no change in MDM2 and p53 expressions in H1299 cells. A549 cells treated with Nutlin-3a or paclitaxel demonstrated a slight increase in wild-type p53 and MDM2 protein, but those treated with Nutlin-3a plus paclitaxel showed significant upregulation. Conversely, there was almost no increase in wild-type p53 and MDM2 protein in H1299 cells treated with Nutlin-3a and/or paclitaxel.

\subsection{Cell cycle arrest by Nutlin-3a and paclitaxel}

To determine if Nutlin-3a inhibition of MDM2 affects progression through the cell cycle, A549 and H1299 cells were treated with a vehicle or Nutlin-3a followed by paclitaxel. The percentage of cells in each stage of the cell cycle was then determined using flow cytometry. As shown in Figure 1(a), A549 cells treated with Nutlin-3a alone showed a decrease in the proportion in the $\mathrm{S}$ phase $(11.4 \%$ vs. $27 \%$ control), a greater increase in the percentage of cells in G0-G1 ( $72.1 \%$ vs. $59 \%$ control), and a slight increase in the percentage of cells in G2-M (16.5\% vs. $14 \%$ control). A549 cells treated with Nutlin-3a plus paclitaxel showed a marked increase in the number of cells in G0-G1 (71.7\%) and G2-M phase $(20.9 \%)$, and a significant decrease in the percentage of cells in the $\mathrm{S}$ phase (7.4\%). In contrast, there was almost no change in cell cycle distribution following administration of Nutlin-3a and/or paclitaxel (Figure 2(a)).

\subsection{Nutlin-3a protects wild-type p53 cells from paclitaxel-induced apoptosis}

The percentage of apoptotic A549 cells treated with $10 \mu \mathrm{mol} / \mathrm{L}$ Nutlin-3a plus $10 \mathrm{nmol} / \mathrm{L}$ paclitaxel was $13.7 \% \pm 1.67 \%$, which was significantly lower compared with that in H1299 cells $(34.8 \% \pm 3.52 \%, P<0.05)$ (Figure 2(b)). (a)

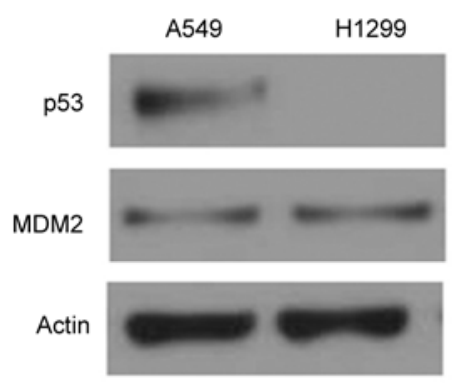

(b)

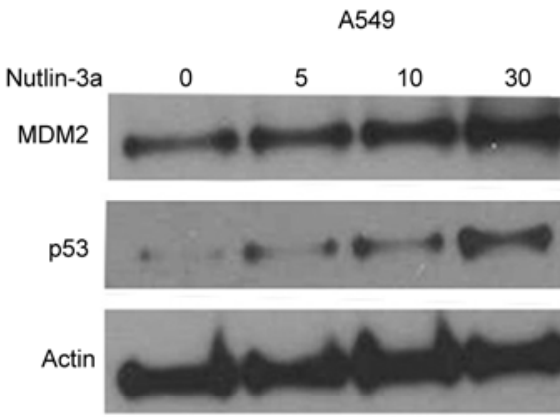

(d) (c)

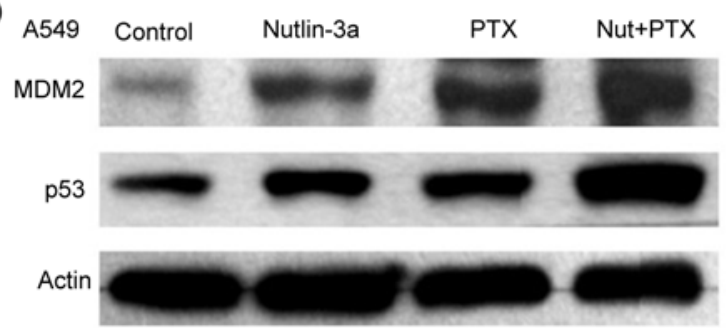

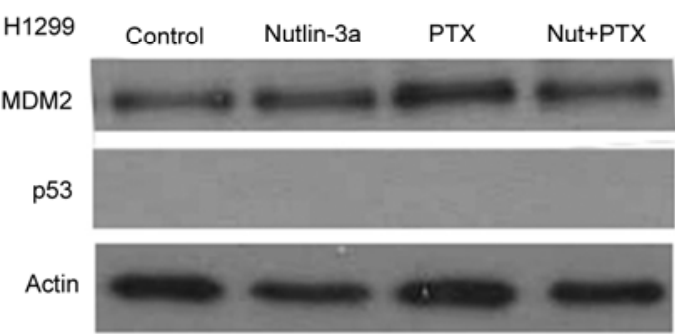

Figure 1 (a) Expression of MDM2 and wild-type p53 in A549 and H1299 cells or (b) in A549 and H1299 cells treated with varying concentrations of Nutlin-3a $\left(0,5,10,30 \mu \mathrm{mol} / \mathrm{L}\right.$ ). (c) A549 and (d) H1299 cells were incubated in $25-\mathrm{cm}^{2}$ flasks in $5-\mathrm{mL}$ medium for $8 \mathrm{~h}$ with vehicle (untreated control), $10 \mu \mathrm{mol} / \mathrm{L}$ Nutlin-3a, $10 \mathrm{nmol} / \mathrm{L}$ paclitaxel, or a combination of $10 \mu \mathrm{mol} / \mathrm{L}$ Nutlin-3a and $10 \mathrm{nmol} / \mathrm{L}$ paclitaxel. Expressions of MDM2 and wild-type p53 protein were determined using Western blot. PTX, paclitaxel; Nut, Nutlin-3a. 

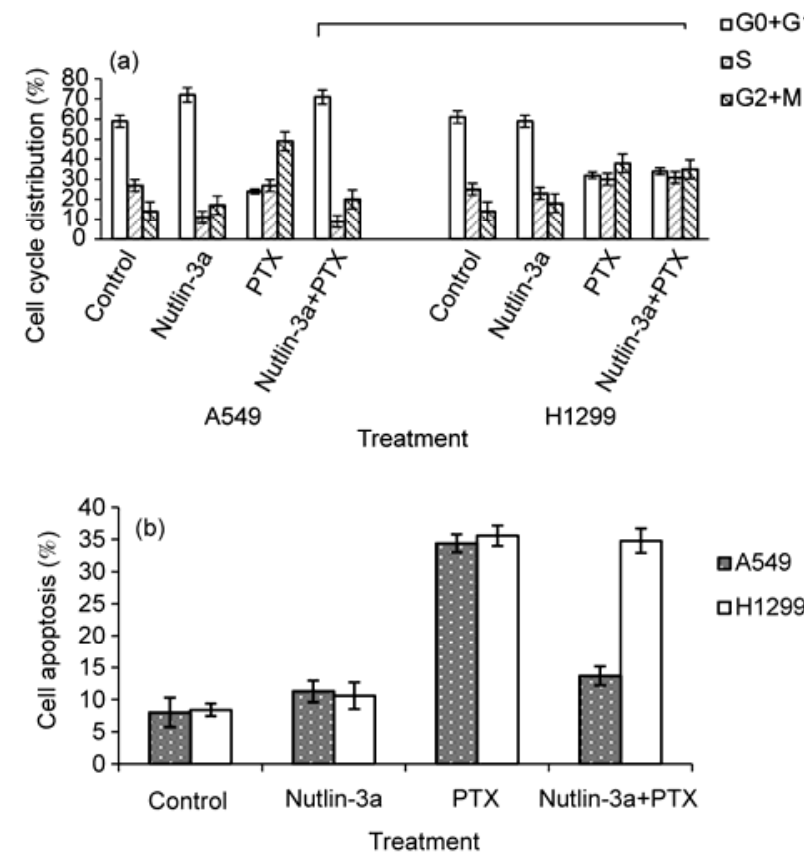

Figure 2 Cell cycle distribution and apoptosis. (a) Effect of Nutlin-3a and paclitaxel (PTX) on cell cycle arrest. Cell cycle distribution following $24 \mathrm{~h}$ treatment with DMSO (control), $5 \mu \mathrm{mol} / \mathrm{L}$ Nutlin-3a, $10 \mathrm{nmol} / \mathrm{L}$ PTX or a combination of $5 \mu \mathrm{mol} / \mathrm{L}$ Nutlin-3a pre-treatment for $24 \mathrm{~h}$ and then 10 nmol/L PTX. (b) Apoptosis induced by $5 \mu \mathrm{mol} / \mathrm{L}$ Nutlin-3a, $10 \mathrm{nmol} / \mathrm{L}$ PTX or a combination of $5 \mu \mathrm{mol} / \mathrm{L}$ Nutlin-3a and $10 \mathrm{nmol} / \mathrm{L}$ PTX for $48 \mathrm{~h}$. Percentage of apoptotic cells was determined by flow cytometry. $* P<0.05$.
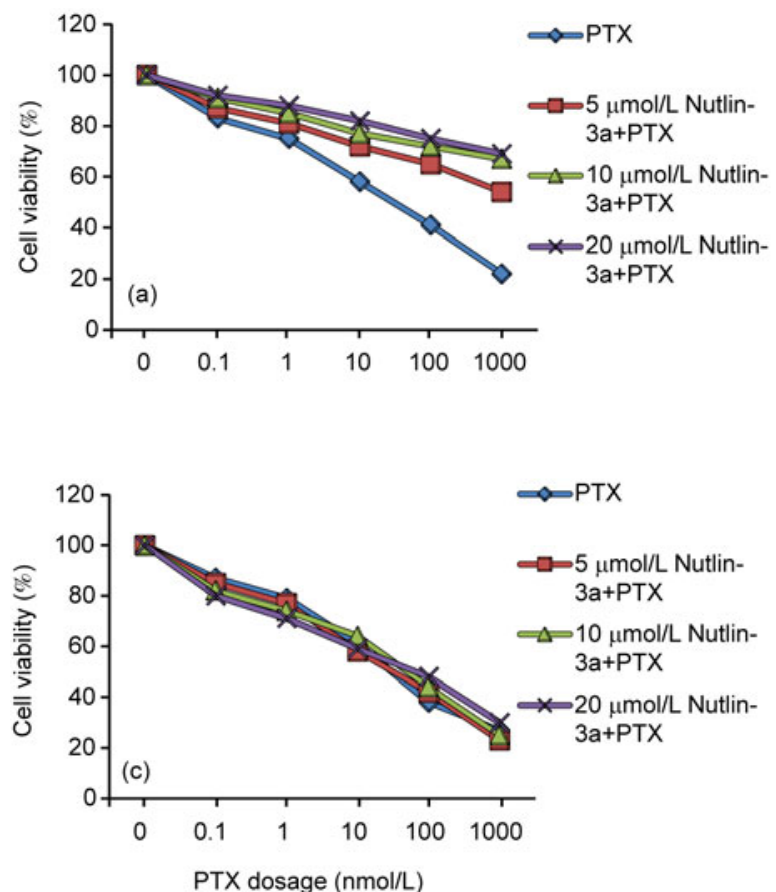

\subsection{Nutlin-3a reduces sensitivity of wild-type p53 cells to paclitaxel}

A549 and H1299 cell lines were exposed to increasing doses of paclitaxel alone or in combination with 5,10 or $20 \mu \mathrm{mol} / \mathrm{L}$ Nutlin-3a for 72 h. Nutlin-3a plus paclitaxel significantly reduced the sensitivity of A549 cells compared with that in H1299 cells $(P<0.05)$ (Figure 3). In another experiment, A549 and $\mathrm{H} 1299$ cells were pretreated with $10 \mu \mathrm{mol} / \mathrm{L}$ Nutlin-3a for $24 \mathrm{~h}$, and/or treated with $10 \mathrm{nmol} / \mathrm{L}$ paclitaxel for an additional 24, 48 or $72 \mathrm{~h}$. Nutlin-3a protected A549 cells from paclitaxel (Figure 3).

\section{Discussion}

Chemotherapy is the main treatment modality for most NSCLC patients, but there are many side-effects, such as hematologic toxicity, gastrointestinal reaction, second malignancies and drug hypersensitivity. Hence, there is an urgent need to reduce the dosage of chemotherapeutic agents and to sensitize cancer cells to chemotherapy. However, caution must be exercised when choosing the right agents to sensitize cells to chemotherapy.

The $p 53$ tumor suppressor gene controls the activity of multiple genes involved in cell aging, cell cycle arrest, and apoptosis [20]. The p53 has an important role in preventing
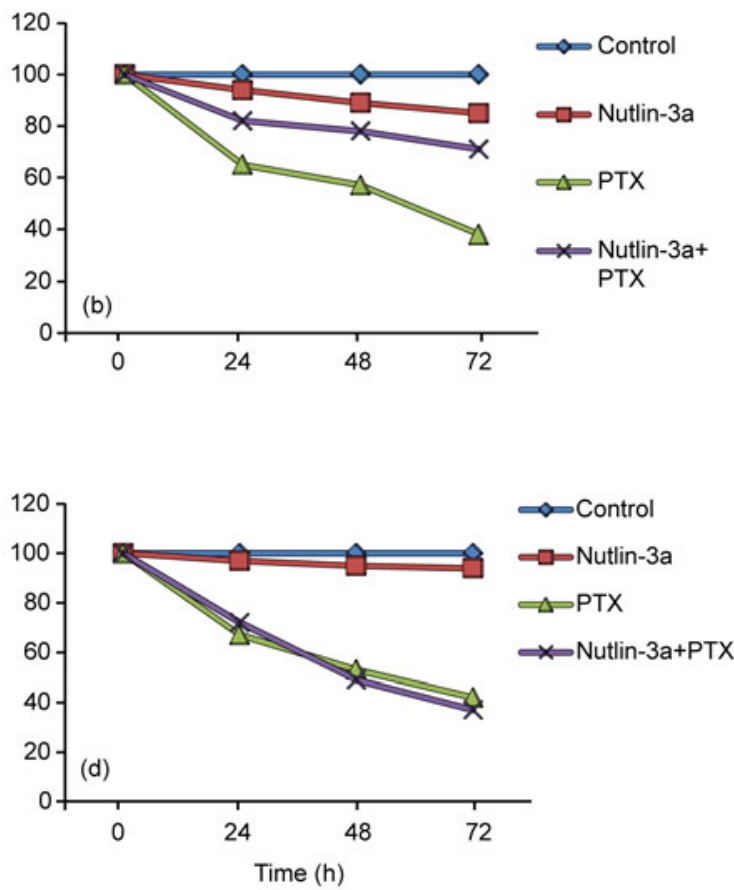

Figure 3 Cell survival percentage was determined using MTT assays. (a), (c) A549 and H1299 cell lines were exposed to increasing doses of paclitaxel (PTX) alone or in combination with 5, 10 and $20 \mu \mathrm{mol} / \mathrm{L}$ Nutlin-3a for $72 \mathrm{~h}$. Nutlin-3a significantly protects A549 cells from PTX in comparison with H1299 cells $(P<0.05)$. (b), (d) A549 and H1299 cell lines were pre-treated with $10 \mu \mathrm{mol} / \mathrm{L}$ Nutlin-3a for $24 \mathrm{~h}$, and/or treated with $10 \mathrm{nmol} / \mathrm{L}$ PTX for an additional 24,48 or $72 \mathrm{~h}$. 
tumor formation through transcription-dependent and transcription-independent pro-apoptotic activities. One major function of $\mathrm{p} 53$ is the activation of G1-S and G2-M checkpoints of the cell cycle through transcriptional stimulation of p21 [21]. The p53 also can trigger mitochondrial outer membrane permeabilization and apoptosis in the absence of transcription through direct activation of Bax or Bak or through binding to Bcl-2 or Bcl-XL. The expression of wildtype p53 in most NSCLC represents a potent molecular target for therapy [22].

As a main regulator of tumorigenesis and progression, MDM2 inhibits the expression of wide-type p53, suggesting that the inhibition of MDM2 partially contributes to the elevated activity of wild-type p53 in NSCLC [23,24]. MDM2 and p53 form a negative feedback loop [12], which is very important for tumorigenesis. If the feedback loop is interrupted by an agent such as Nutlin-3a, the tumor cell will undergo apoptosis. Nutlin-3a has been studied as an effective agent to induce cell cycle arrest and apoptosis in some tumors, and has been found to increase radiosensitivity of H460 and Val138 cells [16], and to sensitize cells to chemotherapeutic agents such as cisplatin and etoposide [17]. To date, there has been no study of Nutlin-3a as a chemosensitizer for the commonly used agent paclitaxel.

In our study, we detected the expression of MDM2 and wild-type p53 in A549 and H1299 cells treated with paclitaxel or paclitaxel plus Nutlin-3a using Western blot. We found that A549 cells treated with Nutlin-3a plus paclitaxel showed a significant upregulation of MDM2 and wild-type p53 proteins, but this effect was not observed in H1299 cells undergoing the same treatment regime. These results showed that Nutlin-3a effectively inhibited the activity of MDM2 and enhanced the wild-type p53 activity, and that there was a synergistic effect of Nutlin-3a and paclitaxel in wild-type p53 cells.

Paclitaxel is a cell cycle-dependent chemotherapeutic that targets mitotic cells. A549 cells treated with Nutlin-3a alone showed a greater increase in the percentage of cells in G0-G1 phase. A549 cells treated with Nutlin-3a plus paclitaxel showed a marked increase in the number of cells in G0-G1 and G2-M phase, and a significant decrease in the percentage of cells in the $S$ phase. Nutlin-3a could arrest cell cycle at the G0-G1 and G2-M phases in these cells. Nutlin-3a plus paclitaxel protected wild-type p53 cells from the cytotoxic effects of paclitaxel. However, Nutlin-3a had no effect on the cell cycle of p53-deficient (H1299) cells, suggesting it has no protecting effect. The percentage of apoptotic A549 cells treated with $5 \mu \mathrm{mol} / \mathrm{L}$ Nutlin-3a plus $10 \mathrm{nmol} / \mathrm{L}$ paclitaxel was significantly lower than those only treated with paclitaxel, and compared with the effect observed in H1299 cells. Proliferation assay results showed that Nutlin-3a plus paclitaxel also significantly reduced A549 cell sensitivity to paclitaxel compared with H1299 cells. Considering all this evidence, Nutlin-3a appears to interrupt the MDM2-p53 feedback loop. The elevation of p53 affected the expression of down- stream genes such as $p 21, \mathrm{Bcl}-2, \mathrm{Bax}$, causing cell cycle arrest in the G0-G1 and G2-M phases, which results in resistance to mitotic chemotherapeutics such as paclitaxel. Therefore, the combination of Nutlin-3a and mitotic chemotherapeutics is not a wise choice for treatment of cancers expressing wild-type p53.

In conclusion, Nutlin-3a mediates the cytotoxic effect of paclitaxel depending on the p53 status. It may protect wildtype p53 cells from mitotic chemotherapeutics, and therefore it is necessary to choose combined chemotherapeutic agents with caution and to develop treatments individually.

This work was supported by the National High-Tech Research and Development Program of China (2007AA021802) and the Provincial Natural Science Foundation of Shandong (ZR2010HM067 and ZR2011HM077). There is no conflict of interest for all authors.

1 Parkin D M, Bray F, Ferlay J, et al. Global cancer statistics, 2002. CA Cancer J Clin, 2005, 55: 74-108

2 Paredes L A, Blanco G C, Echenique E M, et al. Expression of proteins associated with multidrug resistance and resistance to chemotherapy in lung cancer. Arch Bronconeumol, 2007, 43: 479-484

3 Sörenson S, Glimelius B, Nygren P, et al. A systematic overview of chemotherapy effects in non-small cell lung cancer. Acta Oncol, 2001, 40: 327-339

4 Lowe S W, Cepero E, Evan G. Intrinsic tumour suppression. Nature, 2004, 432: 307-315

5 Vogelstein B, Lane D, Levine A J. Surfing the p53 network. Nature, 2000, 408: 307-310

6 Oliner J D, Kinzler K W, Meltzer P S, et al. Amplification of a gene encoding a p53-associated protein in human sarcomas. Nature, 1992, 6381: 80-83

7 Vogelstein B, kinzler K W. p53 function and dysfunction. Cell, 1992, 4: 523-526

8 Bond G L, Hu W, Levine A J. MDM2 is a central node in the p53 pathway: 12 years and counting. Curr Cancer Drug Targets, 2005, 5: 3-8

9 Oliner J D, Pietenpol J A, Thiagalingam S, et al. Oncoprotein MDM2 conceals the activation domain of tumour suppressor p53. Nature, 1993, 362: 857-860

10 Freedman D A, Wu L, Levine A J. Functions of the MDM2 oncoprotein. Cell Mol Life Sci, 1999, 55: 96-107

11 Momand J, Jung D, Wilczynski S, et al. The MDM2 gene amplification database. Nucleic Acids Res, 1998, 26: 3453-3459

12 Michael D, Oren M. The p53-Mdm2 module and the ubiquitin system. Semin Cancer Biol, 2003, 13: 49-58

13 Espinoza-Fonseca L M. Targeting MDM2 by the small molecule RITA: Towards the development of new multi-target drugs against cancer. Theor Biol Med Model, 2005, 2: 1-6

14 Fry D C, Graves B, Vassilev L T. Development of E3-substrate (MDM2-p53) binding inhibitors: Structural aspects. Methods Enzymol, 2005, 399: 622-633

15 Fry D C, Vassilev L T. Targeting protein-protein interactions for cancer therapy. J Mol Med, 2005, 83: 955-963

16 Cao C, Shinohara E T, Subhawong T K, et al. Radiosensitization of lung cancer by nutlin, an inhibitor of murine double minute 2. Mol Cancer Ther, 2006, 5: 411-417

17 Barbieri E, Mehta P, Chen Z, et al. MDM2 inhibition sensitizes neuroblastoma to chemotherapy-induced apoptotic cell death. Mol Cancer Ther, 2006, 5: 2358-2365

18 Jiang M, Pabla N, Murphy R F, et al. Nutlin-3 protects kidney cells during cisplatin therapy by suppressing Bax/Bak activation. J Biol Chem, 2007, 282: 2636-2645

19 Carvajal D, Tovar C, Yang H, et al. Activation of p53 by MDM2 an- 
tagonists can protect proliferating cells from mitotic inhibitors. Cancer Res, 2005, 65: 1918-1924

20 Harris S L, Levine A J. The p53 pathway: Positive and negative feedback loops. Oncogene, 2005, 24: 2899-2908

21 Iliakis G, Wang Y, Guan J, et al. DNA damage checkpoint control in cells exposed to ionizing radiation. Oncogene, 2003, 22: 5834-5847

22 Dworakowska D, Gózdz S, Jassem E, et al. Prognostic relevance of proliferating cell nuclear antigen and p53 expression in non-small cell lung cancer. Lung Cancer, 2002, 35: 35-41

23 Shangary S, Wang S. Targeting the MDM2-p53 interaction for cancer therapy. Clin Cancer Res, 2008, 14: 5318-5324

24 Patel S, Player M R. Small-molecule inhibitors of the p53-HDM2 interaction for the treatment of cancer. Expert Opin Investig Drugs, 2008, 17: 1865-1882

Open Access This article is distributed under the terms of the Creative Commons Attribution License which permits any use, distribution, and reproduction in any medium, provided the original author(s) and source are credited. 